Supporting information:

\title{
Optimization of Pore Structure of Cathodic Carbon Supports for Solvate Ionic Liquid Electrolytes- Based Lithium-Sulfur Batteries
}

Shiguo Zhang, ${ }^{\star}$ Ai Ikoma, ${ }^{\star}$ Zhe Li, Kazuhide Ueno, Xiaofeng Ma, Kaoru Dokko, and Masayoshi Watanabe*

Department of Chemistry and Biotechnology, Yokohama National University, 79-5 Tokiwadai, Hodogaya-ku, Yokohama 240-8501, Japan

E-mail: mwatanab@ynu.ac.jp 


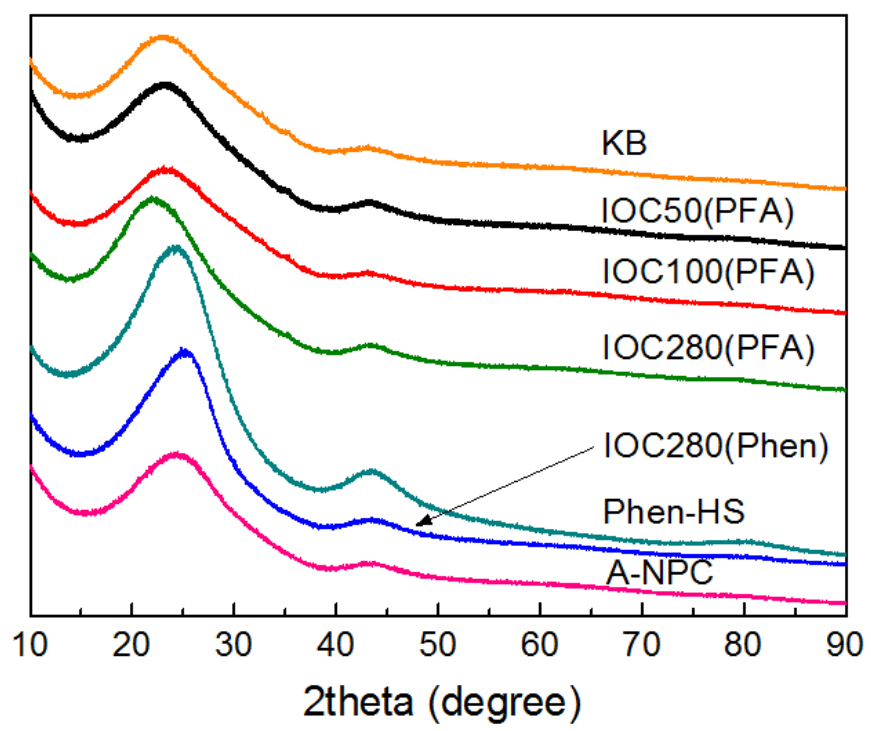

Figure S1. XRD patterns of carbons.

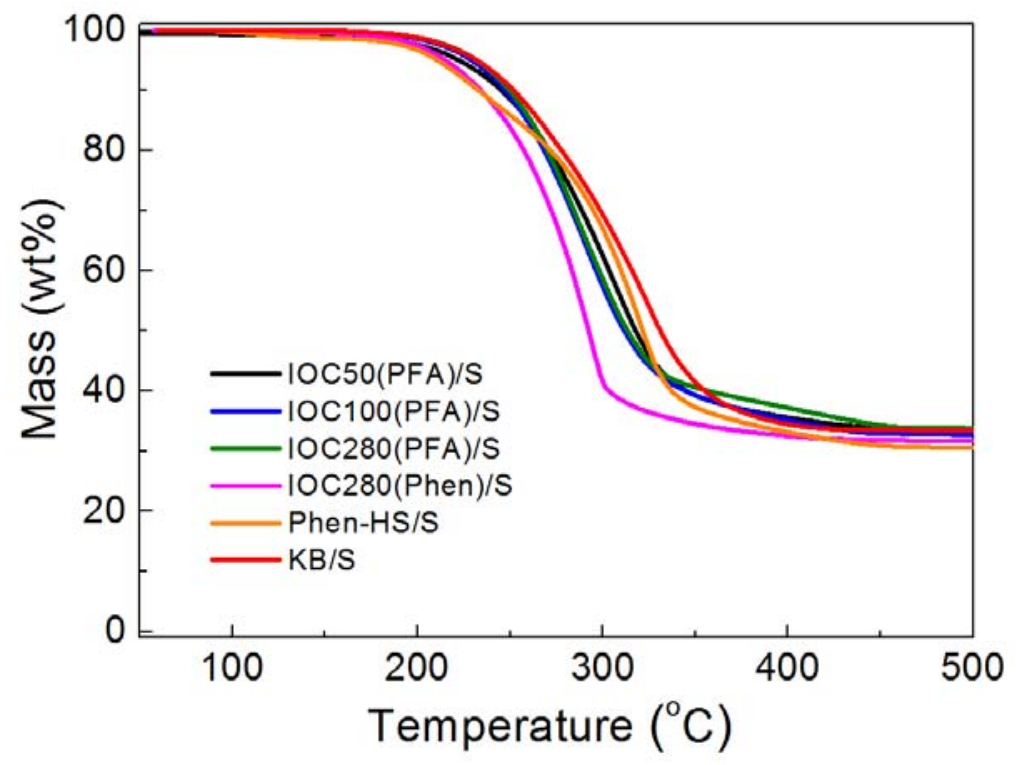

Figure S2. TGA curves of the C/S composites. 


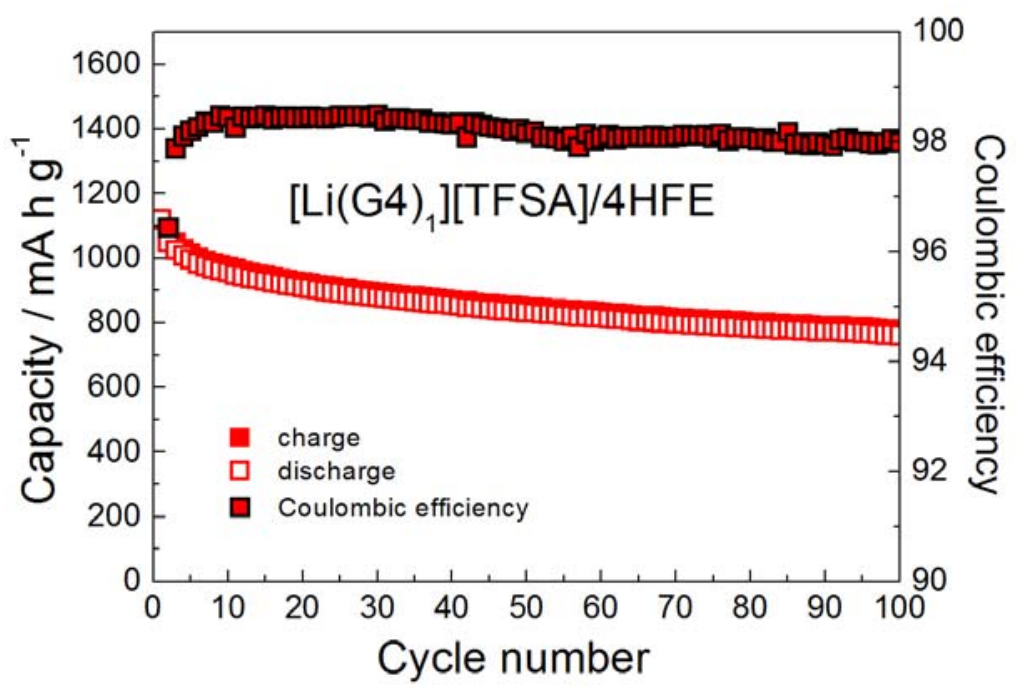

Figure S3. Charge-discharge profile, cycle performance and Coulombic efficiency of $\mathrm{IOC}_{50}(\mathrm{PFA}) / \mathrm{S}$ cathode within $\left[\mathrm{Li}(\mathrm{G} 4)_{1}\right][\mathrm{TFSA}] / 4 \mathrm{HFE}$ at a current rate of $139 \mathrm{~mA} / \mathrm{g}$-sulfur $\left(\mathrm{C} / 12\right.$ rate) at $30^{\circ} \mathrm{C}$.

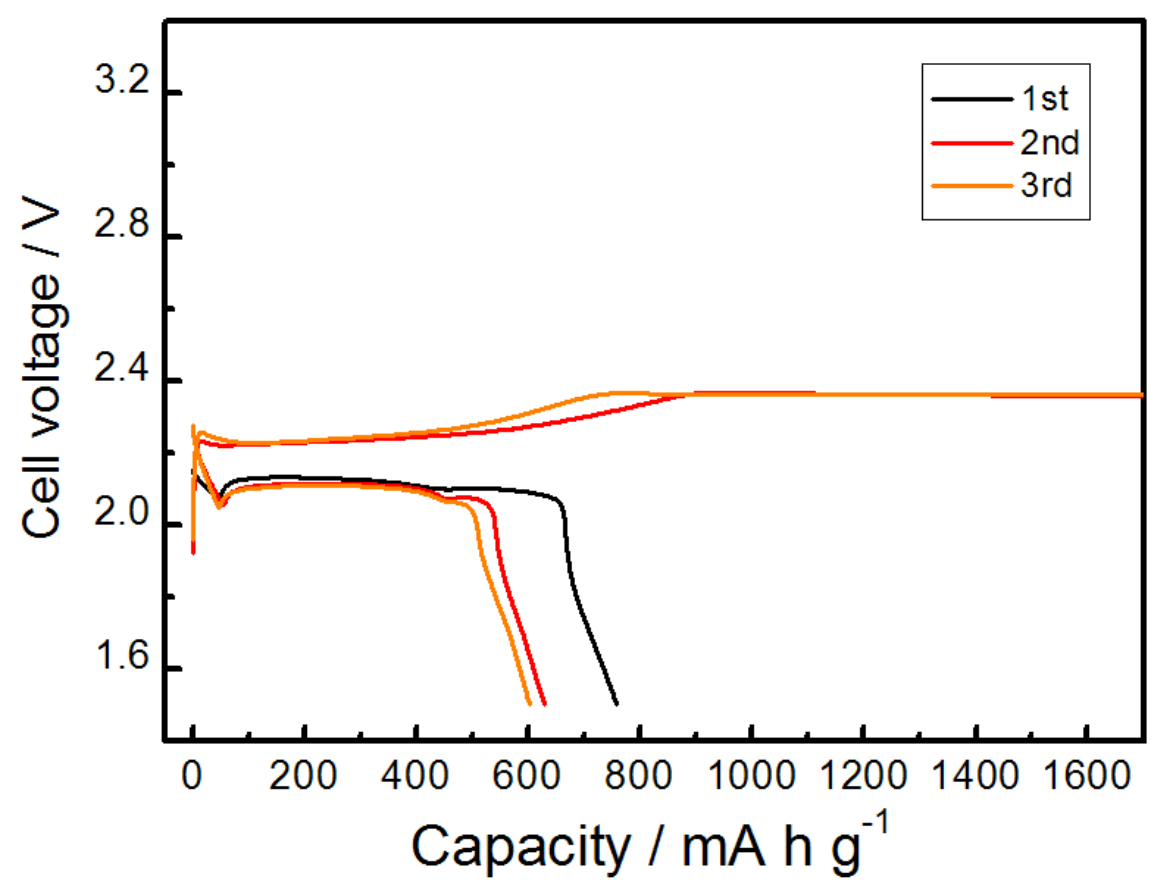

Figure S4. Charge-discharge profile of $\operatorname{IOC}_{50}(\mathrm{PFA}) / \mathrm{S}$ cathode within LiTFSA-DOL/DME at a current rate of $139 \mathrm{~mA} / \mathrm{g}$-sulfur $(\mathrm{C} / 12$ rate $)$ at $30^{\circ} \mathrm{C}$. 
Table S1 Filling ratio of sulfur in pores of different carbon materials.

\begin{tabular}{|l|r|}
\hline Carbon & Filling ratio of S $(\%)^{a}$ \\
\hline IOC $_{50}(\mathrm{PFA})$ & 29.4 \\
$\mathrm{IOC}_{100}(\mathrm{PFA})$ & 41.4 \\
$\mathrm{IOC}_{280}$ (PFA) & 48.3 \\
$\mathrm{IOC}_{280}(\mathrm{Phen})$ & 318.6 \\
$\mathrm{Phen} \mathrm{HS}$ & 69.4 \\
$\mathrm{~KB}$ & 62.1 \\
$\mathrm{~A}-\mathrm{NPC}$ & 100.8 \\
\hline
\end{tabular}

${ }^{a}$ Filling ratio $100 \%$ means that the $\mathrm{Li}_{2} \mathrm{~S}$ fills $100 \%$ of the pore volume of carbon when the $\mathrm{S}$ is completely converted to $\mathrm{Li}_{2} \mathrm{~S}$ within the composite cathode. 